\title{
Lições da Teoria da Reação Social Para o Estudo da Resistência aos Crimes de Estado
}

\author{
Vernon Araújo Corrêa Simões \\ Mestre em Direito pela Faculdade de Direito de Vitória - FDV - e especializado em Criminologia pelo Cesv. http://lattes.cnpq. \\ br/8815722218398945. vernon.acs@gmail.com \\ Thiago Fabres de Carvalho \\ Doutor e mestre em Direito pela Universidade do Vale do Rio dos Sinos - Unisinos. Realizou Estágio de Doutoramento pela Universi- \\ dade de Coimbra (2006). Docente no curso de Mestrado e Doutorado no Programa de Pós-Graduação Stricto Sensu em Direitos e Ga- \\ rantias Fundamentais da Faculdade de Direito de Vitória - FDV. http://lattes.cnpq.br/3188834949695960. thiagofabres@gmail.com
}

RESUMO

O propósito deste artigo é contribuir para a disseminação de um saber criminológico ainda restrito na academia brasileira: a criminologia de crimes de estado. A partir das produções teóricas de Green e Ward, a problemática que instigou esta pesquisa foi a possibilidade de resistir aos crimes de estado. A hipótese de que é possível articular resistência contra crimes de estado por meio de lições da teoria da reação social, é desenvolvida dialogando algumas dessas lições com a criminologia dos crimes de estado e com as consequências da reação social na resistência. A escolha da teoria da reação social decorreu da importância simbólica do "crime", situando seu manejo pelas agências de controle, pela mídia e pela sociedade civil. Apesar da existência de alguns problemas que a utilização do símbolo "crime" pode trazer, estes são inerentes às disputas do campo hegemônico, restando aos atores sociais dar o tom da sua utilização.

Palavras-chave: Crimes de estado. Resistência. Reação social.

\section{LESSONS FROM SOCIAL REACTION THEORY TO THE STUDY OF RESISTANCE TO STATE CRIME}

\section{ABSTRACT}

The purpose of this article is to contribute to the dissemination of a still restricted criminological knowledge in the Brazilian academy: the criminology of state crimes. From the theoretical productions of Green and Ward, the problem that instigated this research was the possibility of resisting state crimes. The hypothesis that it is possible to articulate resistance against state crimes through lessons from the social reaction theory is developed by discussing some of these lessons with state crimes criminology and with the consequences of social reaction as resistance. The choice of the social reaction theory stems from the symbolic importance of "crime", placing its management by the control agencies, the media and civil society. Despite the existence of the problems that the use of the symbol "crime" can bring, these are inherent in the disputes of the hegemonic field, leaving to the social actors to give the tone of their use.

Keywords: State crime. Resistance. Social reaction.

SUMÁRIO

1 Introdução. 2 A Criminologia de Crimes de Estado. 3 Crime: A Palavra Mágica. 4 O Símbolo como Resistência. 50 Problema do Controle. 6 Conclusão. 7 Referências. 


\section{INTRODUÇÃO}

O propósito deste artigo é contribuir para a disseminação de um saber criminológico ainda restrito na academia brasileira: a criminologia de crimes de estado. A partir das produções teóricas de Green e Ward (State Crime: Governments, Violence and Corruption, 2004 e State Crime, Human Rights, and the Limits of Criminology, 2000), a problemática que instigou esta pesquisa foi a possibilidade de resistir, controlar e reduzir os crimes de estado.

A busca direcionada à resposta do problema na literatura especializada revelou a demasiada abrangência deste, desvelando a necessidade de restringi-lo para que uma investigação mais robusta pudesse ser feita. Muitas são as formas pelas quais os crimes de estado são percebidos (FRIEDRICHS, 2009-2010, p. 13), e também são muitas as possibilidades de resistência (FRIEDRICHS, 2009-2010; LASSLETT, 2012). Seu manejo completo exigiria optar por uma de duas possíveis ações: ou catalogá-las - incompatível com a pretensão científica da elaboração de um artigo - ou exauri-las - o que exigiria a elaboração de um tomo escrito por mais de uma mão.

Por tal razão, o problema levantado inicialmente sofreu dois recortes em sua estrutura. Tanto a forma de resistir ao crime de estado foi especializada, quanto a abrangência dos crimes de estados foi reduzida. Agora, o problema, adaptado às pretensões de uma pesquisa científica, tomou a forma que moldou o presente artigo sem deixar de exprimir a angústia do problema inicial: se é possível resistir aos crimes de estado praticados no estado de direito por meio da reação social direcionada.

Por ser um trabalho essencialmente teórico, o método investigativo ficou restrito à revisão bibliográfica dentro da produção criminológica - o que pode ser percebido na própria reformulação da problemática da pesquisa. Além da categoria criminológica de crimes de estado, partimos da análise do processo de reação social, observado pelas teorias interacionistas da reação social como forma de resistência. Ainda que em alguns pontos do artigo tenham sido levantadas leituras que apenas dialogam com (mas não compõe) essas áreas, foi neste campo do conhecimento que a investigação se pautou.

A narrativa construída com o objetivo de expor a pesquisa foi propositalmente ordenada, de forma que o primeiro tópico constituísse uma introdução à criminologia de crimes de estado, focando nas teorias de Green e Ward (2000, 2004). Logo, conceitos como crime, estado, crime de estado, desvio e dano, serão problematizados e explicados como são trabaIhados no campo da criminologia de crimes de estado.

Munidos das ferramentas conceituais necessárias para a compreensão parcial da pesquisa, apresentamos o segundo tópico como uma preparação do por que escolher buscar na teoria da reação social lições para o estudo da resistência aos crimes de estado. Assim, o tópico versará sobre a importância simbólica da etiqueta "crime", situando seu manejo pelas agências de controle, pela mídia e pela sociedade civil, completando o percurso inicial do trabalho. 
Passamos, então, ao terceiro tópico, no qual a hipótese de que é possível articular resistência contra crimes de estado por meio de lições da teoria da reação social, é desenvolvida. O objetivo deste tópico é, além de tudo, dialogar postulados das teorias da reação social com os crimes de estado e com as consequências da criminalização das instituições oficiais de controle social pela sociedade civil.

O quarto e último tópico, antes da conclusão da pesquisa, tem a pretensão de tecer algumas considerações sobre possíveis problemas do uso do símbolo crime como meio de resistência aos crimes de estado. Essas considerações serão expostas com foco específico sobre a possibilidade de apropriação do símbolo por determinadas elites para se valerem de interesses próprios.

Por fim, será concluído que, apesar da existência de alguns problemas que a utilização do símbolo crime pode trazer, estes são inerentes às disputas do campo hegemônico, restando aos atores sociais dar o tom da sua utilização. Não é possível, entretanto, negar a existência de efeitos positivos que a apropriação desse símbolo pode trazer na resistência às violações ilegítimas de direitos humanos, principalmente àquelas cuja resistência é reivindicada por setores ideologicamente díspares da sociedade.

\section{A CRIMINOLOGIA DE CRIMES DE ESTADO}

Antes das escolas sociológicas do crime, o discurso dominante na criminologia foi o de que essa estaria adstrita ao estudo do crime como definido por lei. Não foram poucas as concepções que surgiram como tentativa de relativizar a epistemologia do crime. Willem A. Bonger, por exemplo, referia-se ao crime como um "sério ato antissocial ao qual o estado reage conscientemente pela inflição de sofrimento", ou, também, Sutherland, que relacionou o conceito de crime aos conceitos de "injúria social", "injusto" e "injúria ao estado" (apud SCHWEDINGER; SCHWENDIGER, 1980, p. 138).

A ruptura do limite epistemológico legalista do crime não ocorreu sem disputa. Paul Tappan, intelectual da criminologia tradicional, criticou os reformistas quanto à vagueza que a ruptura acarretaria, apontando sua insuficiência para definir os rótulos decorrentes do saber criminológico, defendendo que o conceito de crime permanecesse restringido à sua concepção legalista, para que ainda fosse possível manejar um estudo criminológico científico (apud SCHWEDINGER; SCHWENDIGER, 1980, p. 138).

Apesar, no entanto, de a concepção social representar uma ruptura aos limites epistemológicos da criminologia tradicionalista, ela ainda apresenta um limite às possibilidades de estudo dos crimes de estado. A concepção legalista é insuficiente para tratar de crimes de estado porque tranca o conceito de crime dentro das limitações ao próprio poder de punir do estado. A concepção social também é insuficiente porque o estado não age como indivíduo inserido em uma sociedade, mas, sim, como instituição.

Por essa razão, seria necessária uma nova visada ou ruptura epistemológica do crime para conseguir estudarmos crimes de estado. Assim, Green e Ward (2000) buscam entender o crime de estado independente dos critérios legais e sociais, utilizando como parâmetro o conceito de direitos humanos junto ao conceito de desvio. 
Green e Ward (2000) destacam que não é sempre que crimes de estado serão afrontas aberrantes aos direitos humanos, podendo, muitas vezes, vir em forma de rotinas sustentadas no combate à criminalidade (a exemplo do "uso moderado da força").

Para que seja possível definir o que são os crimes de estado, eles apontam a necessidade de diferenciar os conceitos de dano e de crime (GREEN; WARD, 2000, p. 104). Enquanto o conceito de dano é atrelado à ideia de injúria social, à mera causação do dano, o conceito de crime está preocupado com o dano causado em situações de desvio. Por isso a criminologia dos crimes de estado não pode ser confundida com a zemiologia, estudo dos danos sociais.

O crime de estado seria a união entre o dano - uma violação aos direitos humanos - e o desvio. O conceito de desvio, aqui, diferente de sua intenção original, não deve ser entendido apenas como comportamento desviante, mas, sim, como uma questão de legitimidade, averiguada na análise concreta das ações do estado sobre o parâmetro dos valores que o vinculam (sociais e institucionais) e suas regras/normas - uma questão de congruência (GREEN; WARD, 2000, p. 109).

O estudo dos crimes de estado não constitui apenas uma exposição da violência e da capacidade de desumanização que estruturas estatais podem exercer, mas, sim, o engajamento de um projeto de desmistificação de uma ideologia de poder, como bem-afirma Ross et al. (1999, p. 277-278). Trabalhar com crimes de estado é, necessariamente, trabalhar com processos de poder que tornam algumas violações à direitos humanos crimes e outras não. Entender o objeto de estudo como fruto de processos de poder nos permite propor algumas intervenções a práxis que orientem o poder para direções de resistência.

A maioria dos crimes de estado passa despercebida pela população e, quando conseguem atenção (ou por grandes mídias ou por movimentos populares), eles costumam gerar escândalos (MARKOVITZ; SILVERSTEIN apud ROSS, 1998, p. 332) ou crises de legitimidade (HABERMAS apud ROSS, 1998). Para que seja possível fazer resistência aos crimes de estado, é necessário instrumentalizar a resistência para que estes crimes não sejam enxergados como exceções ao estado de direito, mas como crimes.

Uma das opções de instrumentalização da resistência aos crimes de estado é a possibilidade de torná-los objeto de controle. Como denota Ross (1999, p. 333), o controle é uma categoria de estudo dentro da administração pública, existindo um vasto conhecimento sobre técnicas e ações voltadas aos atos desviantes de departamentos governamentais. O problema reside no fato de ser costumeiro que intervenções da administração pública com o objeto de controlar resultem em novos crimes de estado.

Por isso, o meio sugerido para instrumentalização da resistência está no campo da reação social. Dentro do estado de direito, identificar determinadas ações estatais como crime pode exercer um efeito de controle - o mero identificar pode gerar reação social capaz de interferir na esfera política de forma a resistir ao crime de estado.

\section{CRIME: A PALAVRA MÁGICA}

As teorias da reação social foram inovadoras em seu tempo ao partirem da premissa de que a diferença no tratamento entre comportamentos devia menos à valoração social do que à definição legal que o definiu como criminoso ou não criminoso (BARATTA, 2002, p. 85-86). 
Alguns dos problemas que tomam o esforço dos autores que trabalham as teorias da reação social são sobre quem é definido como desviante, sobre qual efeito decorre desta definição sobre o indivíduo, sobre quais condições este indivíduo precisa para se tornar objeto de uma definição e sobre quem define quem.

Aos leitores, no entanto, é necessário esclarecer que as teorias da reação social não têm por objeto a análise de desvios institucionais: são teorias sociológicas que se ocupam com as reações das instâncias oficiais de controle social e as reações sociais, considerando seu papel criminalizante de desvios. São teorias que estudam o efeito estigmatizante da atividade policial, jurisdicional e carcerária, e como a sociedade interage com o estigma.

As teorias da reação social são orientadas em duas direções: uma que estuda a "identidade" desviante, categorizada como desvio secundário (efeito da aplicação da etiqueta de criminoso), outra que estuda o problema da distribuição do poder de definição, principalmente nas agências de controle social (BARATTA, 2002, p. 89). A presente pesquisa abrirá mão da análise de criminalização secundária, com o intuito de dialogar, especialmente, sobre as premissas teóricas da distribuição do poder de definição - em especial referente à possibilidade do etiquetamento do estado pelo senso comum.

Ainda dentro dessa orientação das teorias da reação social, elencamos como alvo do diálogo o que, para Lemert (1967, p. 17), seria uma das duas questões mais importantes dentro de uma teoria da criminalidade: como os atos desviantes são ligados simbolicamente e as consequências dessa ligação para os atos desviantes sucessivos. A escolha pontual desse aspecto das teorias da reação social tem o intuito de dialogar seus postulados com um saber criminológico de vertente crítica, de forma que premissas epistemológicas não se desalinhem.

Para entender os processos de definição derivados do senso comum a partir das análises dos interacionistas fenomenológicas, é preciso compreender o desvio (não institucional) como um processo no qual alguns indivíduos inseridos em grupos interpretam determinado comportamento como desviante; assim, criam uma definição correspondente à uma pessoa cujo comportamento remeta a como o desvio é percebido e passam a tratá-la de forma diferenciada (KITSUSE, 1962, p. 94).

Para começar uma reação social, é necessário que o comportamento desviante consiga intervir na rotina, criando alguma forma de indignação, irritação ou embaraço (BARATTA, 2002, p. 95). Não basta o simples desvio. A dimensão simbólica que o desvio recebe ao desencadear uma reação social, no entanto, é o que denota o diálogo pretendido entre as teorias nesta pesquisa.

A reação social exige que o comportamento desviante e indignante seja definido como tal. Esse processo de definição é condicionado socialmente a análises de situações anteriores, somente se realizando em razão da função simbólica que ele exerce (BARATTA, 2002, p. 97). Uma situação somente é considerada passível de gerar reação social se assemelhar-se a algum referente simbólico de situação anteriormente prevista como passível de reação social.

Ao analisar essa estrutura associativa, a dúvida que paira é como as situações anteriores são simbolicamente reconhecidas na situação nova. Para os interacionistas, a linguagem simbólica das situações anteriores constitui o próprio fundamento da situação nova. Se não houvesse símbolos já cristalizados, a situação nova sequer seria reconhecida como desviante. 
É mais fácil pensar nesta estrutura quando passamos para o âmbito jurídico. Essa facilidade decorre da semelhança estrutural na qual se produzem novos "símbolos jurídicos": pela utilização de analogias e precedentes utilizamos símbolos criados por situações anteriores (precedentes ou normas) para significar uma nova situação que nos é apresentada.

A figura jurídica do crime, no entanto, possui uma capacidade simbólica ímpar. Por algum motivo, o crime tomou o espaço do imaginário coletivo como objeto de asco. Quando uma conduta é criminalizada, a reação social deixa de reagir a um fato desviante, passando a reagir a seu novo significante: o crime. A situação não mais precisa ser desviante ou indignante, pois o rótulo crime as garante como tal. Basta o rótulo de crime e a indignação é criada, não mais fazendo parte fundamental da equação da reação social (excluindo grupos onde estão presentes técnicas de neutralização). Por que, porém, o crime ocupa esse espaço simbólico?

Christie (2011, p. 33-49) responde que nas sociedades modernas vivemos na monoinstitucionalização do paradigma/instituição do comércio, da produção e da circulação de dinheiro. Essa monoinstitucionalização ocasiona a criminalização de condutas conforme dá valor simbólico ao crime. Podemos ver essa valorização do crime como palco de disputa política, a punição como principal medida mantenedora da ordem pública e a constante criação dos inimigos públicos (2011, p. 65-66).

O papel simbólico que o crime assumiu como palco político ocorreu em razão da ausência de outros espaços públicos que garantissem a mesma legitimidade para outras pautas em estados enfraquecidos. O crime como símbolo consegue dar legitimidade para ações que dizem representar múltiplos grupos diferentes, independente de determinadas pautas políticas.

\section{O SÍMBOLO COMO RESISTÊNCIA}

O crime como símbolo está posto, mas padece da exclusividade que o estado detém sobre a sua concepção legalista. A tomada do símbolo por meio do saber criminológico apresentado, no entanto, é exatamente o que se propõe aqui. A utilização do símbolo crime para gerar reação social ante a violações desviantes dos direitos humanos por parte do estado, é um caminho de resistência.

Não é fácil tomar esse símbolo - ainda mais pela quantidade de tempo em que ele ficou sobre domínio do Estado. Por isso, são necessárias formas de instrumentalizar a sua apropriação, resolvendo a questão de como a sociedade civil pode apropriar em sua linguagem comum o símbolo crime de estado.

A disputa é pelo campo da hegemonia, que se refere a uma ordem falada da linguagem moral comum (GREEN; WARD, 2004). É necessário incutir no pensamento hegemônico que violações ilegítimas aos direitos humanos correspondam a crimes de estado. Para isso, é necessário que, no pensamento hegemônico, essas violações assemelhem-se ao referente simbólico crime. 
A mais importante lição de Gramsci (1971) é a relevância que ele dá para a sociedade civil em sua capacidade de disseminar essa linguagem moral comum. Essa hegemonia representa um espaço entre a estrutura estatal e as esferas particulares que costuma ser ocupado por organizações, como associações, coletivos, grupos religiosos, a grande mídia e a academia (GREEN; WARD, 2004, p. 4).

Esses grupos criam opiniões e têm objetivos com os que tentam influenciar a opinião pública e as estruturas governamentais. São instituições extraoficiais de controle que têm a capacidade de etiquetar condutas não desejadas e modificar o comportamento daqueles etiquetados. Para que a reação social seja um meio de resistência, a criminalização do estado deve partir de grupos organizados, capazes de disputar o campo da hegemonia.

Diferentemente da pretensão abolicionista de abrir mão do campo simbólico que rodeia o sistema penal, para que esse tipo de resistência funcione é necessário abraçar a existência do símbolo crime. É preciso que instituições extraoficiais de controle que desejam ser grupos de resistência utilizem o crime como o palco político que ele representa. Ao utilizar do símbolo crime para combater violações ilegítimas dos direitos humanos por parte do Estado, a adoção de estratégias de criminalização secundária torna-se obrigatória. É preciso criar cerimônias degradantes para ritualizar a criminalização do Estado.

Para teóricos da reação social, as cerimônias degradantes são rituais que submetem o indivíduo desviante para tomar sua identidade original e transformá-lo em um indivíduo criminoso (SHECARIA, p. 313-315; DIAS; ANDRADE, 1992, p. 350). Essa cerimônia é o processo pelo qual a associação de símbolos relacionados ao crime é atribuída a uma nova conduta ou a uma nova pessoa.

Ao resistir aos crimes de estado, instituições extraoficiais de controle devem criar seus próprios rituais de criminalização, uma vez que não disporá do processo criminal, alicerce das cerimônias degradantes. Esses rituais devem ocupar espaços públicos, reivindicando pela fala o reconhecimento das violações ilegítimas aos direitos humanos como crime, com o único intuito de fortalecer um novo símbolo. Ao fortalecerem o símbolo crime de estado, estarão criando um referente simbólico para que novas situações sejam associadas ao símbolo, moldando a linguagem moral comum bem como a própria moral comum. Assim, o próprio símbolo apropriado vira uma fonte de resistência.

\section{O PROBLEMA DO CONTROLE}

Apesar da possibilidade de apropriação do símbolo crime em prol da criminalização do estado, é necessário considerar as possibilidades de que a apropriação ocorra por determinados grupos para cumprir agendas próprias.

Para Ross (1998, p. 332), quando crimes de estado são reconhecidos como tal três situações costumam acontecer. A primeira é a tentativa de controle externo por parte de instituições extraoficiais de controle, que buscam criar reação social suficiente para influenciar nas estruturas estatais (controle simbólico). A segunda é a tentativa de controle interno por parte das próprias estruturas estatais, que busca responder à reação social promovida a fim de contornar uma crise de legitimidade (controle tangível). A terceira situação consiste nas consequências específicas dessas intervenções. 


\section{Humanos}

Democracia

É muito comum que tentativas de controlar crimes de estado resultem em outros crimes de estado. É uma dicotomia natural e necessária do controle em razão da sua natureza dialética. Por exemplo, a omissão proposital de segurança pública em determinados locais pode ser respondida com aumento da segurança pública, criando problemas referentes ao uso de força ilegal.

O problema passa a ser real quando o controle é recheado de intenções de grupos específicos, podendo chegar até à censura de algumas instâncias extraoficiais, participantes políticos ou ativistas por outros. Ao retomar ao exemplo, se a reação social causada pela omissão proposital de segurança pública for guiada por instituições ou pessoas ligadas a empresas do setor armamentista, é provável que a resposta não atenda aos anseios da sociedade civil.

Outro problema é o papel que a grande mídia pode exercer na reação social. Apesar de sua essencialidade na exposição dos crimes de estado, seu envolvimento pode acarretar direcionamentos que não atendam interesses sociais. É comum que as grandes mídias sejam controladas por empresas que estão politicamente alinhadas com o estado (ROSS, 1998, p. 335), e seu grau de exposição sobre os fatos é proporcional ao alinhamento.

Ainda, sobre as grandes mídias, é preciso ressaltar que a própria exposição dos crimes de estado é seletiva (assim como ocorrem com os crimes comuns), o que pode levar a utilização do símbolo crime para guiar seletivamente a reação social, a fim de favorecer interesses particulares ligados à economia ou a política.

Se por um lado as grandes mídias têm recursos e divulgação suficiente para fazer esse controle, por outro ele é exercido de forma direcionada a interesses de ordem financeira (lucro na divulgação) ou ideológica (aliança com governos). Ainda, apesar da crescente democratização do conhecimento por intermédio de meios alternativos de informe proporcionados pela internet, a ramificação das informações oriundas desses meios ainda não é suficiente para mobilizar forças de controle (ROSS, 1999, p. 335).

Resistir e controlar os crimes de estado requer constante exercício de criticidade. É necessário entender quais processos de disputa por poder permeiam as tentativas de resistência e controle, e como a influenciam. É preciso pensar quais instituições extraoficiais de controle estão realizando as cerimônias degradantes e porque fazem isso, reconhecendo posicionamentos ideológicos.

Os problemas elencados, no entanto, são problemas que já permeiam qualquer área que tangencia o campo hegemônico: sempre existirão cabos de força disputando símbolos de poder. Apesar disso, ainda teremos crimes de estado cuja resistência será reivindicada independentemente de disputas hegemônicas (por exemplo, as violações de direitos básicos como saúde e educação).

\section{CONCLUSÃO}

Ao olharmos para a estrutura associativa das situações desviantes dentro das teorias da reação social, percebemos a possibilidade de utilizar a linguagem simbólica, que permeia o símbolo crime, com o intuito de ressignificar violações ilegítimas dos direitos humanos. Para isso, atribuir às violações o rótulo de crime é a conexão que fundamentará como a nova situação (crime de estado) será percebida. 
Para que essa simbologia incorpore o senso comum, permeando a linguagem moral comum, é necessária intervenção de instituições extraoficiais de controle. Essas instituições poderão recorrer às chamadas cerimônias degradantes, mas de forma adaptada à sua realidade extraoficial (sem processo criminal). Essas cerimônias deverão buscar que o reconhecimento das violações ilegítimas de direitos humanos ocupe espaços públicos, lutando por um lugar na linguagem moral comum.

O problema dessa estratégia de resistência aos crimes de estado é a possibilidade de que instituições extraoficiais de controle passem a usar da linguagem simbólica com o objetivo de direcionar novas criminalizações, ou dispersar criminalizações que deveriam ser feitas. Apesar desse problema, existente em qualquer disputa hegemônica, a criminalização de violações ilegítimas de direitos humanos por parte do estado ainda é capaz de exercer o efeito de resistência pretendido.

\section{REFERÊNCIAS}

BARATTA, A. Criminologia crítica e crítica do direito penal: introdução à sociologia do direito penal. 3. ed. Rio de Janeiro: Editora Revan; Instituto Carioca de Criminologia, 2002.

CHRISTIE, N. Uma razoável quantidade de crime. Rio de Janeiro: Revan, 2011.

DIAS, J. F.; ANDRADE, M. C. Criminologia: o homem delinquente e a sociedade criminógena. Coimbra: Coimbra Ed., 1992.

FRIEDRICHS, D. O. On Resisting State Crime: Conceptual and Contextual Issues. Social Justice, v. 36 n. 3, p. 4-27, 2009-2010. Disponível em: https://www.jstor.org/stable/29768546?seq=1\#page_scan_tab_contents. Acesso em: 8 nov. 2016.

GRAMSCI, A. Selections from the Prison Notebooks. Londres: Lawrence \& Wishart, 1971.

GREEN, P. J.; WARD, T. State Crime, Human Rights, and the Limits of Criminology. Social Justice, v. 27 n. 1, p. $101-$ 114, 2000. Disponível em: https://www.jstor.org/stable/29767193. Acesso em: 2 nov. 2016.

GREEN, P. J.; WARD, T. State Crime: Governments, Violence and Corruption. London: Pluto Press, 2004.

KITSUSE, J. I. Societal reaction to deviant behavior: problems of theory and method. Social Problems, v. 9 n. 3, p. 247-256, 1962. Disponível em: http://socpro.oxfordjournals.org/content/9/3/247. Acesso em: 8 set. 2016.

LASSLETT, K. Power, Struggle and State Crime: researching through resistance. State Crime Journal v. 1, n. 1, p. 126-148, 2012. Disponível em: http://www.jstor.org/stable/41917774?seq=1\#page_scan_tab_contents. Acesso em: 9 set. 2016.

LEMERT, E. M. Human Deviance, Social Problems, \& Social Control. Nova York: Prentice Hall, 1967.

ROSS, J. I. Situating the academic study of controlling state crime. Crime, Law \& Social Change v. 29, 4, p. 331340, 1998. Disponível em: http://link.springer.com/article/10.1023\%2FA\%3A1008248216731. Acesso em: 6 jun. 2016.

ROSS, J. I. et al. The State of State Crime Research - a commentary. Humanity \& Society, v. 23 n. 3, p. 273-281, 1999. Disponível em: http://has.sagepub.com/content/23/3/273.full.pdf+html. Acesso em: 2 nov. 2016.

SHECARIA, S. S. Criminologia. 3. ed. São Paulo: Edita Revista dos Tribunais, 2011.

SCHWENDIGER, H.; SCHWENDIGER, J. Defensores da ordem ou guardiões dos direitos humanos? In: TAYLOR, I.; WALTON, P.; YOUNG, J. (org.). Criminologia crítica. Tradução Juarez C. S. e Sergio T. Rio de Janeiro: Edições Graal, 1980. 